\title{
Regional differences in presentation characteristics, use of treatments and outcome of patients with cardiogenic shock: Results from multicenter, international registry
}

\author{
Michal Pazdernik ${ }^{\mathrm{a}, \mathrm{b}}$, Mario Gramegna', Allan Bohm ${ }^{\mathrm{d}, \mathrm{e}}$, Maria Trepa ${ }^{\mathrm{f}}$, Christophe Vandenbriele ${ }^{\mathrm{g}}$, Salvatore De Rosah, \\ Jamol Uzokov', Milica Aleksic, Milana Jarakovick, Mohammad El Tahlawi', Morsy Mostafam ${ }^{\mathrm{m}}$, Maria Stratinakin, \\ Diego Araiza-Garaygordobil ${ }^{\circ}$, Ekaterina Gubareva ${ }^{p}$, Polina Duplyakova ${ }^{q}$, Manuel Chacon-Diaz', Hesham Refaat ${ }^{\text {ts, }}$ \\ Federico Guerra ${ }^{t}$, Alberto Maria Cappellettic, Vojtech Berka ${ }^{b}$, Dirk Westermann ${ }^{u}$, Benedikt Schrage ${ }^{u}$
}

\begin{abstract}
Background. Concurrent evidence about cardiogenic shock (CS) characteristics, treatment and outcome does not represent a global spectrum of patients and is therefore limited. The aim of this study was to investigate these regional differences.

Methods. To investigate regional differences in presentation characteristics, treatments and outcomes of patients treated with all types of cardiogenic shock (CS) in a single calendar year on a multi-national level. Consecutive patients from 19 tertiary care hospitals in 13 countries with CS who were treated between January 1, 2018 and December 31 , 2018 were enrolled in this study.

Results. In total, 699 cardiogenic shock patients were included in this study. Of these patients, 440 patients (63\%) were treated in European hospitals and 259 (37\%) were treated in Non-European hospitals. Female patients $(P<0.01)$ and patients with a previous myocardial infarction $(P=0.02)$ were more likely to present at Non-European hospitals; whereas older patients $(P=0.01)$ and patients with cardiogenic shock due to acute heart failure $(P<0.01)$ were more likely to present at European hospitals. Vasopressor use was more likely in Non-European hospitals $(P=0.04)$, whereas use of mechanical circulatory support (MCS) was more likely in European hospitals $(P<0.01)$. Despite adjustment for relevant confounders, 30-day in-hospital mortality risk was comparably high in CS patients treated in European vs. Non-European hospitals (hazard ratio $1.08,95 \% \mathrm{Cl} 0.84-1.39, P=0.56$ ).

Conclusion. Despite marked heterogeneity in characteristics and treatment of CS patients, including fewer use of MCS but more frequent use of vasopressors in Non-European hospitals, 30-day in-hospital mortality did not differ between regions.
\end{abstract}

Kew words: cardiogenic shock, regional differences, mechanical circulatory support, acute heart failure, AMICS

Received: November 3, 2020; Revised: February 17, 2021; Accepted: July 9, 2021; Available online: August 19, 2021

https://doi.org/10.5507/bp.2021.046

(c) 2021 The Authors; https://creativecommons.org/licenses/by/4.0/

a Department of Cardiology, IKEM, Prague, Czech Republic

${ }^{b}$ Department of Cardiology, Second Faculty of Medicine, Charles University and University Hospital Motol, Prague, Czech Republic 'Cardiac Intensive Care Unit, IRCCS San Raffaele Scientific Institute, Milan, Italy

${ }^{d}$ National Cardiovascular Institute, Bratislava, Slovak Republic

e3rd Department of Internal Medicine, Faculty of Medicine, Comenius University, Bratislava, Slovak Republic

${ }^{f}$ Centro Hospitalar Universitario do Porto, Porto, Portugal

'University Hospitals Leuven, Leuven, Belgium

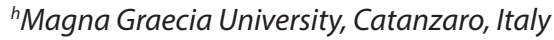

'Republican Specialized Scientific Practical Medical Center of Therapy and Medical Rehabilitation, Tashkent, Uzbekistan

'Clinical Hospital Center Bezanijska Kosa, Belgrade, Serbia

kInstitute for Cardiovascular Diseases of Vojvodina, Sremska Kamenica, Serbia

'Cardiology Department, Zagazig University Hospital, Zagazig, Egypt

${ }^{m}$ As-Salam International Hospital, Cairo, Egypt

${ }^{n}$ Onassis Cardiac Surgery Centre, Athens, Greece

Instituto Nacional de Cardiologia Ignacio Chavez, Mexico City, Mexico

${ }^{p}$ Clinics of Samara State Medical University, Samara, Russian Federation

aSamara State Cardiology Dispensary, Samara, Russian Federation

rInstituto Nacional Cardiovascular-INCOR, Lima, Peru

${ }^{s}$ Al Jahra Hospital, Al Jahra, Kuwait

'Marche Polytechnic University, University Hospital "Umberto I - Lancisi - Salesi", Ancona, Italy

"University Heart and Vasculature Centre, Hamburg, Germany

Corresponding author: Michal Pazdernik, e-mail: michal.pazdernik@email.cz 


\section{INTRODUCTION}

Despite advances in early revascularization and use of mechanical circulatory support (MCS), cardiogenic shock (CS) is still associated with extremely high mortality. Although there is no uniform definition, CS is a low cardiac output state, primarily due to a cardiac dysfunction, resulting in life-threatening end-organ hypoperfusion and hypoxia ${ }^{1}$.

Concurrent evidence about CS characteristics, management and outcome might be hampered by several confounders, as it does not represent a global spectrum of patients. First, patient populations have always been predominantly investigated on a national level, and studies based on multi-national cohorts, especially including nondeveloped countries, are scarce ${ }^{2-4}$. Second, most of the data from registries, observational studies and prospective trials have been derived from high-income countries that possess high quality health care, with more advanced interventional treatment programs, including MCS (ref. ${ }^{5-8}$ ). And third, the vast majority of studies included solely acute coronary syndrome (ACS) related cases, while not including other etiologies, such as myocardial stunning following cardiac arrest or acute heart failure exacerbation $^{9-11}$. This might have a relevant impact, as recent studies indicated that the proportion of CS cases caused by ACS is declining, and that the majority of cases is caused by non-ischemic events ${ }^{4,12}$.

\section{Hypothesis and purpose}

Regional differences in diagnosis, as well as regional differences per se, could influence management and outcome in CS. The aim of this study was to investigate regional differences in presentation characteristics, treatments and outcomes of patients treated with all types of CS in a single calendar year on a multi-national level.

\section{METHODS}

This project was performed in accordance with the Declaration of Helsinki and was approved by the local ethics committees. Need for informed consent was waived as this was a retrospective analysis of anonymized data.

\section{Study population}

From 19 tertiary care hospitals in 13 countries, consecutive patients with CS who were treated between January 1, 2018 and December 31, 2018 were enrolled in a dedicated database. CS, the only inclusion criterion, was defined at the discretion of the local investigator. The only exclusion criterion of this study was age below 18 years. For all included patients, baseline characteristics and in-hospital follow-up were available.

Patients were then stratified as being treated in European countries (Belgium, Czech Republic, Greece, Italy, Portugal, Serbia, Slovakia and Germany) vs. nonEuropean countries (Egypt, Kuwait, Mexico, Peru, Russia and Uzbekistan).

\section{Statistical analysis}

Continuous variables are shown as mean $( \pm$ standard deviation) and compared using t-test; binary variables are

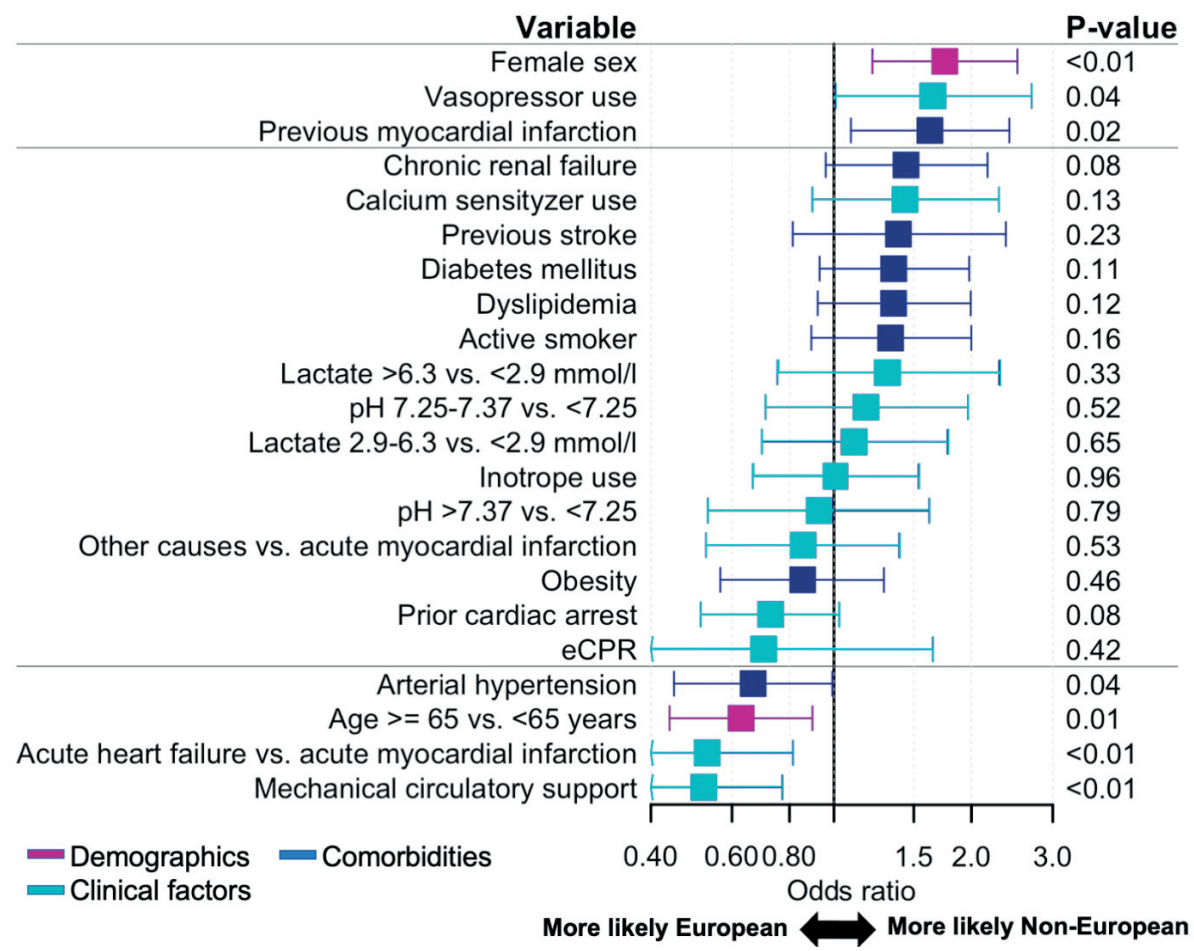

Fig. 1. Differences in presentation characteristics and use of treatments of cardiogenic shock patients treated in European vs. Non-European countries. eCPR: extracorporeal cardiopulmonary resuscitation. 
shown as counts (frequencies) and compared using the $\mathrm{Chi}^{2}$ test.

Missing data were handled by chained equation multiple imputation (10 imputed data sets; $\mathrm{R}$ package mice). Variables used for the imputation of missing data are shown in Table 1.

To assess differences in presentation characteristics and use of treatments between patients with cardiogenic shock treated at European vs. non-European countries, a logistic regression model with location of treatment as the dependent variable and selected presentation characteristics/treatments as independent variables was fitted (Fig. 1).
To assess differences in outcome between patients with CS treated in European vs. non-European countries, the primary endpoint of 30-day in-hospital mortality was analyzed, whereas patients were censored upon discharge from hospital. Survival probabilities were estimated using the Kaplan-Meier method. To assess the association of region of treatment with the primary endpoint, a Cox regression model was fitted, (a) unadjusted and (b) adjusted for age, sex, cause of cardiogenic shock, prior cardiac arrest, extracorporeal cardiopulmonary resuscitation (eCPR), baseline lactate and baseline $\mathrm{pH}$.

A $P$-value of $<0.05$ was considered statistically significant. All analyses were performed with $\mathrm{R}$ statistical software version 3.6.0.

Table 1. Baseline characteristics of the study cohort

\begin{tabular}{|c|c|c|c|c|c|c|}
\hline Variable & $\begin{array}{c}\text { Overall cohort } \\
(n=699)\end{array}$ & $\begin{array}{c}\text { European } \\
(n=440,63 \%)\end{array}$ & $\begin{array}{l}\text { Missing } \\
\text { (\%) }\end{array}$ & $\begin{array}{c}\text { Non-European } \\
(n=259,37 \%)\end{array}$ & $\begin{array}{c}\text { Missing } \\
\text { (\%) }\end{array}$ & $P$ \\
\hline Age, years & $63.90( \pm 14.77)$ & $65.01( \pm 14.01)$ & 0 & $62.01( \pm 15.82)$ & 0 & $<0.01$ \\
\hline Age, $\geq 65$ years & $369(52.8)$ & $243(55.2)$ & & $126(48.6)$ & & 0.11 \\
\hline Female sex & $235(33.6)$ & $133(30.2)$ & 0 & $102(39.4)$ & 0 & 0.02 \\
\hline BMI, $\mathrm{kg} / \mathrm{m}^{2}$ & $27.39( \pm 4.96)$ & $27.21( \pm 4.76)$ & 11.6 & $27.68( \pm 5.25)$ & 5.8 & 0.25 \\
\hline Obesity $\left(\right.$ BMI $\left.>30 \mathrm{~kg} / \mathrm{m}^{2}\right)$ & $451(71.1)$ & $287(73.8)$ & & $164(66.9)$ & & 0.08 \\
\hline Diabetes mellitus & $247(35.6)$ & $136(31.3)$ & 1.4 & $111(42.9)$ & 0 & $<0.01$ \\
\hline Arterial hypertension & $449(64.8)$ & $284(65.4)$ & 1.4 & $165(63.7)$ & 0 & 0.70 \\
\hline Dyslipidemia & $268(38.7)$ & $153(35.3)$ & 1.4 & $115(44.4)$ & 0 & 0.02 \\
\hline Active smoker & $178(25.7)$ & $101(23.3)$ & 1.4 & $77(29.7)$ & 0 & 0.07 \\
\hline Previous myocardial infarction & $189(27.3)$ & $103(23.7)$ & 1.4 & $86(33.2)$ & 0 & $<0.01$ \\
\hline Chronic renal failure & $168(24.2)$ & $94(21.7)$ & 1.4 & $74(71.4)$ & 0 & 0.03 \\
\hline Previous stroke & $72(10.4)$ & $39(9.0)$ & 1.4 & $33(12.7)$ & 0 & 0.15 \\
\hline Systolic blood pressure, $\mathrm{mmHg}$ & $83.52( \pm 23.07)$ & $86.34( \pm 23.74)$ & 17.3 & $79.51( \pm 21.50)$ & 0.8 & $<0.01$ \\
\hline Heart rate, beats per minute & $94.34( \pm 30.48)$ & $96.14( \pm 31.85)$ & 20.9 & $91.89( \pm 28.39)$ & 1.2 & 0.09 \\
\hline Lactate, $\mathrm{mmol} / \mathrm{L}$ & $5.89( \pm 4.99)$ & $6.07( \pm 5.38)$ & 18.2 & $5.55( \pm 4.15)$ & 24.7 & 0.23 \\
\hline Lactate, $<2.9 \mathrm{mmol} / \mathrm{L}$ & $182(32.8)$ & $125(34.7)$ & & $57(29.2)$ & & \multirow{3}{*}{0.42} \\
\hline Lactate, $2.9-6.3 \mathrm{mmol} / \mathrm{L}$ & $186(33.5)$ & $117(32.5)$ & & $69(35.4)$ & & \\
\hline Lactate, $>6.3 \mathrm{mmol} / \mathrm{L}$ & $187(33.7)$ & $118(32.8)$ & & $69(35.4)$ & & \\
\hline $\mathrm{pH}$ & $7.29( \pm 0.15)$ & $7.29( \pm 0.17)$ & 11.6 & $7.29( \pm 0.12)$ & 15.4 & 0.83 \\
\hline $\mathrm{pH},<7.25$ & $195(32.1)$ & $124(31.9)$ & & $71(32.4)$ & & \multirow{3}{*}{0.17} \\
\hline $\mathrm{pH}, 7.25-7.37$ & $220(36.2)$ & $132(33.9)$ & & $88(40.2)$ & & \\
\hline $\mathrm{pH},>7.37$ & $193(31.7)$ & $133(34.2)$ & & $60(27.4)$ & & \\
\hline Cause of cardiogenic shock & & & 0.7 & & 0.4 & \multirow{4}{*}{0.02} \\
\hline Acute myocardial infarction & $422(60.7)$ & $250(57.2)$ & & $172(66.7)$ & & \\
\hline Acute heart failure & $164(23.6)$ & $118(27.0)$ & & $46(17.8)$ & & \\
\hline Other & $109(15.7)$ & $69(15.8)$ & & $40(15.5)$ & & \\
\hline Prior cardiac arrest & $314(44.9)$ & $206(46.8)$ & 0 & $108(41.7)$ & 0 & 0.22 \\
\hline Duration of cardiac arrest, min & $19.81( \pm 25.41)$ & $21.75( \pm 31.04)$ & 10.5 & $16.86( \pm 12.39)$ & 10.4 & 0.10 \\
\hline eCPR & $34(5.5)$ & $24(0.3)$ & 13.2 & $10(4.2)$ & 7.3 & 0.34 \\
\hline Mechanical circulatory support & $210(30.0)$ & $147(33.4)$ & 0 & $63(24.3)$ & 0 & 0.01 \\
\hline IABP & $161(23.0)$ & $98(22.3)$ & & $63(24.3)$ & & 0.60 \\
\hline Impella & $71(10.2)$ & $68(15.5)$ & & $3(1.2)$ & & $<0.01$ \\
\hline ECMO & $80(11.4)$ & $65(14.8)$ & & $15(5.8)$ & & $<0.01$ \\
\hline Vasopressor use & $564(81.9)$ & $346(78.8)$ & 0.2 & $218(87.2)$ & 3.5 & $<0.01$ \\
\hline Inotrope use & $531(77.3)$ & $336(76.5)$ & 0.2 & $195(78.6)$ & 4.2 & 0.59 \\
\hline Calcium sensitizer use & $114(16.4)$ & $69(15.8)$ & 0.5 & $45(17.4)$ & 0.4 & 0.64 \\
\hline Mechanical ventilation & $479(68.7)$ & $309(70.4)$ & 0.2 & $170(65.9)$ & 0.4 & 0.25 \\
\hline
\end{tabular}

Continuous variables are shown as mean ( \pm standard deviation) and compared using t-test; binary variables are shown as counts (frequencies) and compared using the $\mathrm{Chi}^{2}$ test. BMI - body mass index; eCPR- extracorporeal cardiopulmonary resuscitation; ECMO - extracorporeal membrane oxygenation; IABP - intra-aortic balloon pump 


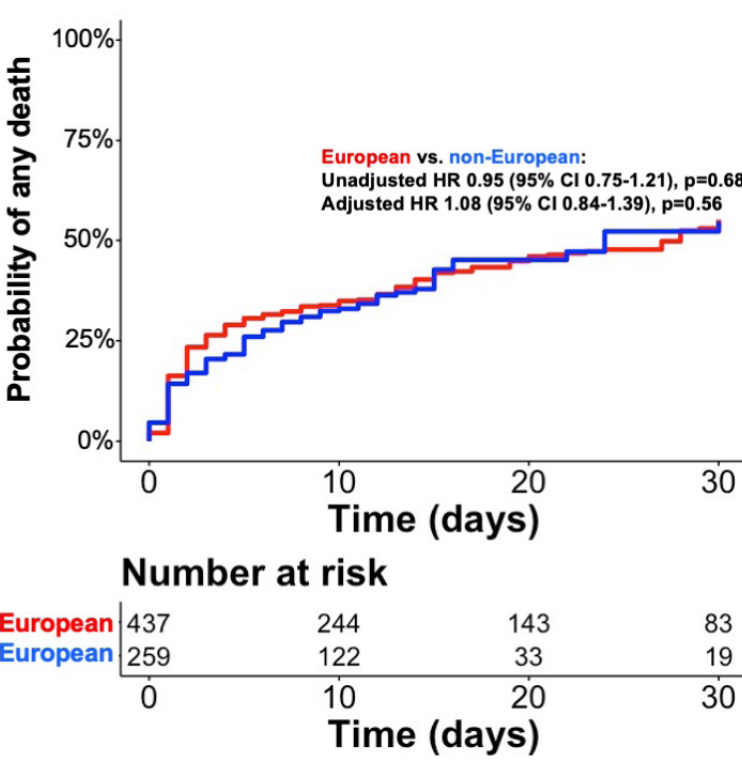

Fig. 2. Outcome in cardiogenic shock patients treated in European vs. Non-European countries.

HR: hazard ratio; CI: confidence interval.

\section{RESULTS}

In total, $699 \mathrm{CS}$ patients were included in this study. Of these patients, 440 patients $(63 \%)$ were treated in European hospitals and 259 (37\%) were treated in NonEuropean hospitals. The mean age of the overall study cohort was $63.90( \pm 14.77)$ years and 235 patients $(33.6 \%)$ were females. Within the overall cohort, 422 patients $(60.7 \%)$ presented with cardiogenic shock due to ACS, 164 patients $(23.6 \%)$ presented with CS due to acute heart failure and 314 patients $(44.9 \%)$ had a prior cardiac arrest. At baseline, mean lactate was $5.89 \pm 4.99 \mathrm{mmol} / 1$ and mean $\mathrm{pH}$ was $7.29 \pm 0.15$. Detailed baseline characteristics per region are shown in Table 1, and baseline characteristics per country are shown in Table 2

\section{Presentation characteristics and use of treatments}

Baseline characteristics in Table 1 are unadjusted. Therefore, we performed multivariable adjusted logistic regression to identify if dedicated presentation characteristics or use of treatments was significantly associated with care at a European vs. a Non-European hospital (Fig. 1). In this analysis, female patients and patients with a previous myocardial infarction were more likely to be treated at Non-European hospitals; whereas older patients, patients with arterial hypertension and patients with CS due to acute heart failure were more likely to be treated at European hospitals. Regarding treatments, vasopressor use was more likely in Non-European hospitals whereas use of MCS was more likely in European hospitals.

\section{Outcome}

During a median follow-up of 10 (interquartile range 4-30) days ( 9 days in European vs. 12 days in NonEuropean patients, $P<0.01$ ), 303 deaths (43.3\%) occurred within 30 days after hospital admission in the overall cohort, corresponding to an unadjusted survival probability of $45 \%$ [95\% confidence interval (CI) 40.2-50.2\%]. Unadjusted survival probabilities in patients treated at European vs. Non-European hospitals were 44.8\% (95\% CI $39.3-50.9 \%$ ) vs. $45.3 \%$ (95\% CI 35.8-57.3\%).

In the unadjusted Cox regression analysis, there was no significant difference in 30-day mortality risk between CS patients treated at European vs. Non-European (hazard ratio $0.95,95 \%$ CI $0.75-1.21, P=0.68$ ). This did not change after adjustment for relevant confounders (hazard ratio $1.08,95 \%$ CI $0.84-1.39, P=0.56$ ) (Fig. 2).

\section{DISCUSSION}

The principal findings from this international registry on CS can be summarized as follows: 1) Despite marked heterogeneity in characteristics and treatment of CS patients, 30-day all-cause mortality did not differ between European and Non-European patients. 2) Patients with CS treated in non-European hospitals were younger, more likely to be female and to have had a prior myocardial infarction, but less likely to have CS due to acute decompensated heart failure. 3) Although, no differences in initial shock severity was observed ( $\mathrm{pH}$, lactate), non-European patients were more likely to be treated with vasopressors, but less likely to be treated with MCS. These findings are of major importance, as they reveal significant regional differences in treatment of CS, although shock severity and mortality risk were comparable between patients treated at European and Non-European hospitals.

Current evidence about CS contains predominantly data derived from single nation registries and studies conducted in developed countries (Germany, USA, France, Switzerland, Japan, etc.) (ref. ${ }^{2-12}$ ) . Notably, as Vallabhajosyula et al. reported in their nationally representative database from the United States, there seems to be a significant geographic heterogeneity in the epidemiology, management and outcomes of CS across one country ${ }^{11}$. Our study confirmed this heterogeneity in terms of causes of CS, clinical presentation, and treatment on a multinational level.

Furthermore, CS has a large phenotypic variability, as result of the diverse etiologies, pathogenetic mechanisms, and stages of severity. In past registries, the significant majority of CS cases in the cardiac intensive care unit was caused by ACS (ref. ${ }^{9-11}$ ). However, the contribution of ACS has declined over the past 2 decades $^{3}$ in parallel with an increase of CS due to other etiologies ${ }^{4,12}$.

The current study spans 19 centers in 13 different countries (6 of them are outside Europe - Africa, Asia and South America) and therefore allows us to report disparities in CS patients across the world.

Average age of patients presenting with CS in Western countries is 67-72 years ${ }^{3,9,11}$, whereas more than a decade lower age at presentation was documented in an Indian cohort with STEMI related CS (ref. ${ }^{13}$ ). We observed a similar trend in our cohort, where younger patients were 


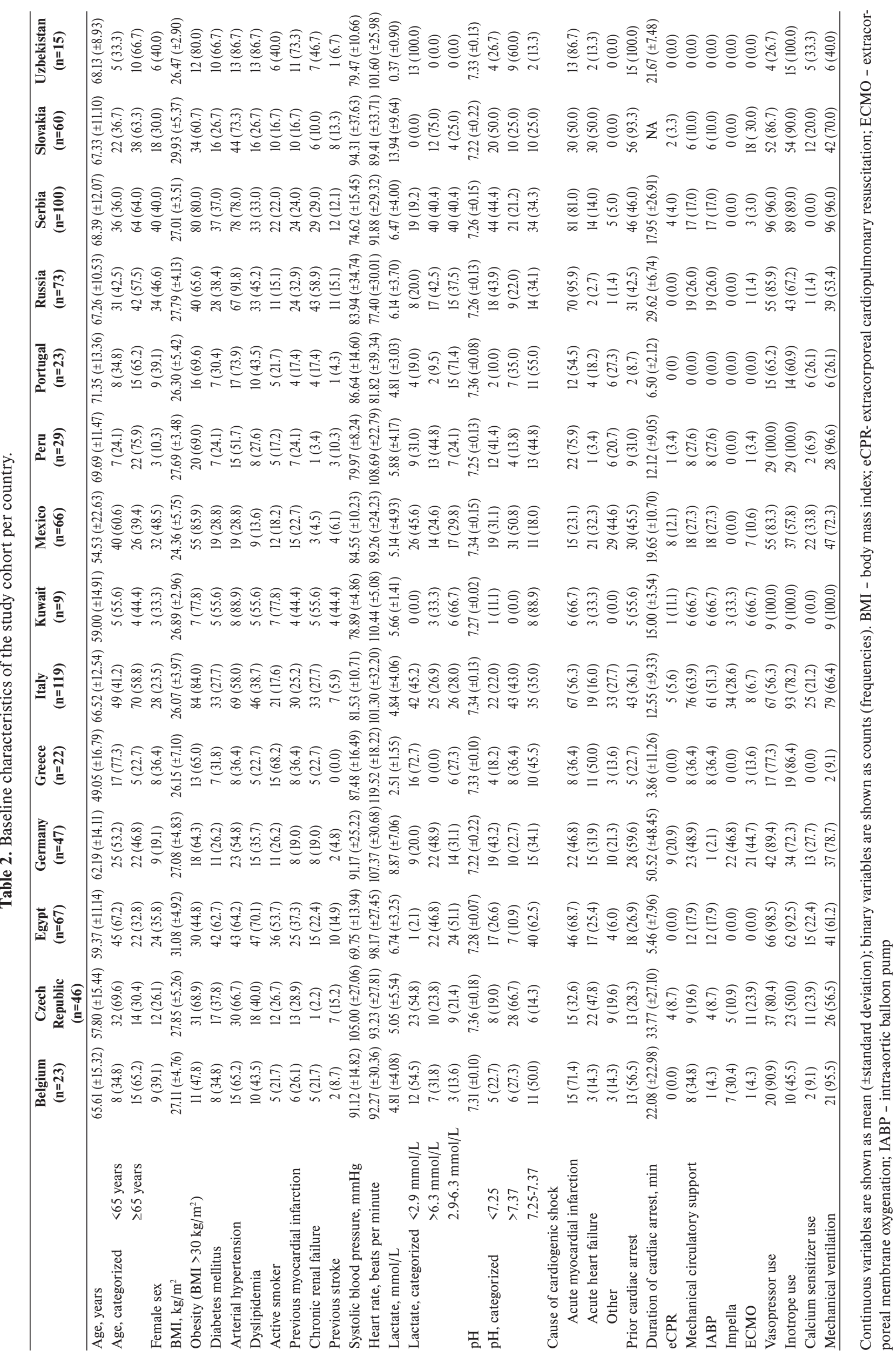


more likely to be recognized in Non-European hospitals. Development of CS remains a particular clinical concern in elderly patients, as multiple studies have identified age as an independent predictor of poor outcomes ${ }^{10,14}$. The previous studies assessing the outcome of elderly patients with CS complicating AMI reported a wide range of mortality rates, from $55 \%$ to $78 \%$ (ref. ${ }^{10,15,16}$ ). Better cardiovascular prevention, and/or near-universal access to high quality healthcare might contribute to generally higher survival and explain higher age at presentation in European patients, as well as different age structures and life expectancies in European vs. Non-European patients.

Representation of females in the previous CS shock studies accounted for $26-37 \%$ (ref. ${ }^{4,9,17}$ ). As part of IABPSHOCK II trial substudy, women had a higher risk profile and seemed to undergo suboptimal treatment in comparison to men, nonetheless no higher mortality rates in short and long-term follow-up for women were observed ${ }^{18,19}$. Contrary, in other studies, both in-hospital and 12-month mortality following MI were significantly higher in women. Also, women experienced CS more often than men ${ }^{20}$. Interestingly, we observed much higher likelihood of female sex in CS patients treated at Non-European hospitals in our cohort, and we may speculate whether there might be an underdiagnosis of females with CS in Europe.

Patients with a previous myocardial infarction were more likely to be treated for CS in Non-European hospitals. In contrast, CS associated with acute heart failure was more likely seen in European centers. This might be an effect of sufficient and high-quality access to revascularization procedures and post-ACS care, including antiplatelet therapy and statins, in European countries; so that patients with ACS treated in European countries might be more likely to survive the initial event and to develop heart failure/CS at a later stage.

Vasopressors are used in the management of patients with CS due to their favorable hemodynamic effect, nevertheless they do not target the underlying problem, while only artificially raising blood pressure. Besides symptomatic improvement, however, there is no compelling evidence suggesting a survival benefit of inotropes and vasopressors $^{21}$. In contrast, MCS might correctly target the underlying problem, which is severe impairment in heart function, allowing the recovery of the heart and the reduction of inotropes/vasopressors use with their detrimental effects ${ }^{22}$. However, MCS utilization has yet to show a favorable impact on survival probabilities ${ }^{7,23,24}$.

CS treatment incurs substantial resource use and costs. MCS is usually not available in low-income countries due to cost restrictions, as well as long-term devices are almost always not affordable ${ }^{25}$. Inadequate access to MCS in majority of Non-European countries was apparent in our cohort. Whereas no major difference was observed in terms of IABP use, significantly higher incidence of Impella or extracorporeal membrane oxygenation insertion use was documented in European patients. Perhaps, this might be the reason why vasopressor use was lower in European countries. Although the benefit of MCS in the treatment of CS has not yet been proven, there is no justification for marginalizing patients not treated in the EU from the latest advances in CS management; and therapeutic advances for CS should be evaluated in all patients, irrespective of region of treatment.

Despite advances in revascularization and MCS, CS mortality is still significantly high, both in European and non-European countries. Gaps in evidence are extensive and relate to the definition, phenotype diversity and management. These gaps might contribute to a large geographical variability in clinical care, including the use of hemodynamic monitoring and timely deployment of $\operatorname{MCS}\left(\right.$ ref. $^{26}$ ).

\section{Limitations}

This study has several limitations. First, no central adjudication of the CS diagnoses was performed. CS, the only inclusion criterion, was defined at the discretion of the local investigator to avoid a preselection of patients. Second, as with all non-randomized data, we cannot exclude an impact of residual or unmeasured confounders. Third, as this study was designed to retrospectively collect the epidemiologic data of CS patients across the globe, not all relevant variables related to CS could be acquired. Fourth, the follow-up was different between patients treated at European vs. Non-European hospitals, which might have had an impact on the observed outcome.

Author contributions: MP, MG, BS - took part in patient recruitment, data analysis and manuscript preparation. AB, MT, CV, SDR, JU, MA, MJ, MET, MM, MS, DAG, EG, PD, MCD, HF, FG, MAC, VB, DW - took part in patient recruitment and manuscript preparation.

Conflict of interest statement: The authors state that there are no conflicts of interest regarding the publication of this article.

Disclosure statement: BS reports speaker's fee from AstraZeneca, unrelated to the current work.

\section{REFERENCES}

1. van Diepen S, Katz JN, Albert NM, Henry TD, Jacobs AK, Kapur NK, Kilic A, Menon V, Ohman EM, Sweitzer NK, Thiele H, Washam JB, Cohen MG. Contemporary Management of Cardiogenic Shock: A scientific statement from the American Heart Association. Circulation 2017;136(16):e232-e268.

2. Harjola VP, Lassus J, Sionis A, Køber L, Tarvasmäki T, Spinar J, Parissis J, Banaszewski M, Silva-Cardoso J, Carubelli V, Di Somma S, Tolppanen $H$, Zeymer U, Thiele H, Nieminen MS, Mebazaa A. Clinical picture and risk prediction of short-term mortality in cardiogenic shock. Eur J Heart Fail 2015;17(5):501-9.

3. Hunziker L, Radovanovic D, Jeger R, Pedrazzini G, Cuculi F, Urban P, Erne P, Rickli H, Pilgrim T. Twenty-year trends in the incidence and outcome of cardiogenic shock in AMIS plus registry. Circ Cardiovasc Interv 2019;12(4):1-9.

4. Berg DD, Bohula EA, van Diepen $\mathrm{S}$, Katz JN, Alviar CL, Baird-Zars VM, Barnett CF, Barsness GW, Burke JA, Cremer PC, Cruz J, Daniels LB, DeFilippis AP, Haleem A, Hollenberg SM, Horowitz JM, Keller N, Kontos MC, Lawler PR, Menon V, Metkus TS, Ng J, Orgel R, Overgaard CB, Park JG, Phreaner N, Roswell RO, Schulman SP, Jeffrey Snell R, Solomon MA, Ternus B, Tymchak W, Vikram F, Morrow DA. Epidemiology of shock in contemporary cardiac intensive care units: Data from the Critical Care Cardiology Trials Network Registry. Circ Cardiovasc Qual Outcomes 2019;12(3):e005618. 
5. Shah M, Patnaik S, Patel B, Ram P, Garg L, Agarwal M, Agrawal S, Arora S, Patel N, Wald J, Jorde UP. Trends in mechanical circulatory support use and hospital mortality among patients with acute myocardial infarction and non-infarction related cardiogenic shock in the United States. Clin Res Cardiol 2018;107(4):287-303.

6. Hochman JS, Buller CE, Sleeper LA, Boland J, Dzavik V, Sanborn TA, Godfrey E, White HD, Lim J, LeJemtel T. Cardiogenic shock complicating acute myocardial infarction - etiologies, management and outcome: a report from the SHOCK Trial Registry. J Am Coll Cardiol 2000;36(3 Suppl A):1063-70.

7. Thiele H, Schuler G, Neumann FJ, Hausleiter J, Olbrich HG, Schwarz B, Hennersdorf M, Empen K, Fuernau G, Desch S, de Waha S, Eite I, Hambrecht R, Böhm M, Kurowski V, Lauer B, Minden HH, Figulla HR, Braun-Dullaeus RC, Strasser RH, Rochor K, Maier SK, Möllmann H, Schneider S, Ebelt H, Werdan K, Zeymer U. Intraaortic balloon counterpulsation in acute myocardial infarction complicated by cardiogenic shock: design and rationale of the Intraaortic Balloon Pump in Cardiogenic Shock II (IABP-SHOCK II) trial. Am Heart J 2012;163(6):938-45.

8. Thiele H, Desch S, Piek JJ, Stepinska J, Oldroyd K, Serpytis $P_{1}$ Montalescot G, Noc M, Huber K, Fuernau G, de Waha S, Meyer-Saraei R, Schneider S, Windecker S, Savonitto S, Briggs A, Torremante P, Vrints C, Schuler G, Ceglarek U, Thiery J, Zeymer U. Multivessel versus culprit lesion only percutaneous revascularization plus potentia staged revascularization in patients with acute myocardial infarction complicated by cardiogenic shock : Design and rationale of CULPRIT-SHOCK trial. Am Heart J 2016;172:160-9.

9. Sakamoto K, Matoba T, Mohri M, Ueki Y, Tsujita Y, Yamasaki M, Tanaka N, Hokama Y, Fukutomi M, Hashiba K, Fukuhara R, Suwa S, Matsuura $\mathrm{H}$, Tachibana E, Yonemoto N, Nagao K. Clinical characteristics and prognostic factors in acute coronary syndrome patients complicated with cardiogenic shock in Japan: analysis from the Japanese Circulation Society Cardiovascular Shock Registry. Heart Vessels 2019;34(8):1241-9.

10. Aissaoui N, Puymirat E, Delmas C, Ortuno S, Durand E, Bataille V, Drouet E, Bonello L, Bonnefoy-Cudraz E, Lesmeles G, Guerot E, Schiele F, Simon T, Danchin N. Trends in cardiogenic shock complicating acute myocardial infarction. Eur J Heart Fail 2020;22(4):66472.

11. Vallabhajosyula $S$, Patlolla $S H$, Dunlay $S M$, Prasad A, Bell MR, Jaffe AS, Gersh BJ, Rihal CS, Holmes DR Jr, Barsness GW. Regional variation in the management and outcomes of acute myocardial infarction with cardiogenic shock in the United States. Circ Heart Fai 2020;13(2):e006661.

12. Schrage B, Weimann J, Dabboura S, Yan I, Hilal R, Becher PM, Seiffert M, Bernhardt AM, Kluge S, Reichenspurner H, Blankenberg S, Westermann D. Patient characteristics, treatment and outcome in non-ischemic vs. ischemic cardiogenic shock. J Clin Med 2020;9(4):931.

13. Sharma YP, Krishnappa D, Kanabar K, Kasinadhuni G, Sharma R, Kishore K, Mehrotra S, Santosh K, Gupta A, Panda P. Clinical characteristics and outcome in patients with a delayed presentation after ST-elevation myocardial infarction and complicated by cardiogenic shock. Indian Heart J 2019;71(5):387-93.

14. Vahdatpour C, Collins D, Goldberg S. Cardiogenic shock. J Am Heart Assoc. 2019;8(8):e011991.

15. Jeger RV, Radovanovic D, Hunziker PR, Pfisterer ME, Stauffer JC, Erne $P$, Urban P. Ten-year trends in the incidence and treatment of cardiogenic shock. Ann Intern Med 2008;149(9):618-26.

16. Lim HS, Andrianopoulos N, Sugumar H, Stub D, Brennan AL, Lim CC,
Barlis P, Van Gaal W, Reid CM, Charter K, Sebastian M, New G, Ajani $A E$, Farouque O, Duffy SJ, Clark DJ. Long-term survival of elderly patients undergoing percutaneous coronary intervention for myocardial infarction complicated by cardiogenic shock. Int J Cardiol 2015; 195:259-64.

17. Helgestad OKL, Josiassen J, Hassager C, Jensen LO, Holmvang L, Udesen NLJ, Schmidt H, Berg Ravn H, Moller JE. Contemporary trends in use of mechanical circulatory support in patients with acute Ml and cardiogenic shock. Open Heart 2020;7(1):e001214.

18. Fengler K, Fuernau G, Desch S, Eitel I, Neumann FJ, Olbrich HG, de Waha A, de Waha S, Richardt G, Hennersdorf M, Empen K, Hambrecht R, Fuhrmann J, Böhm M, Poess J, Strasser R, Schneider S, Schuler G, Werdan K, Zeymer U, Thiele H. Gender differences in patients with cardiogenic shock complicating myocardial infarction: a substudy of the IABP-SHOCK II-trial. Clin Res Cardiol 2015;104(1):71-8.

19. Rubini Gimenez M, Zeymer U, Desch S, de Waha-Thiele S, OuarrakT, Poess J, Meyer-Saraei R, Schneider S, Fuernau G, Stepinska J, Huber K, Windecker S, Montalescot G, Savonitto S, Jeger RV, Thiele H. Sexspecific management in patients with acute myocardial infarction and cardiogenic shock: A substudy of the CULPRIT-SHOCK trial. Circ Cardiovasc Interv 2020;13(3):e008537.

20. Kunadian V, Coats L, Kini AS, Mehran R. Cardiogenic shock in women. Interv Cardiol Clin 2012;1(2):231-43.

21. Belletti A, Castro ML, Silvetti S, Greco T, Biondi-Zoccai G, Pasin L, Zangrillo A, Landoni G. The effect of inotropes and vasopressors on mortality: a meta-analysis of randomized clinical trials. Br J Anaesth 2015;115(5):656-75.

22. Schrage B, Westermann D. Mechanical circulatory support devices in cardiogenic shock and acute heart failure: current evidence. Curr Opin Crit Care 2019;25(4):391-6.

23. Ouweneel DM, Eriksen E, Sjauw KD, van Dongen IM, Hirsch A, Packer EJ, Vis MM, Wykrzykowska JJ, Koch KT, Baan J, de Winter RJ, Piek JJ, Lagrand WK, de Mol BA, Tijssen JG, Henriques JP. Percutaneous mechanical circulatory support versus intra-aortic balloon pump in cardiogenic shock after acute myocardial infarction. J Am Coll Cardiol 2017;69(3):278-87.

24. Schrage B, Ibrahim K, Loehn T, Werner N, Sinning JM, Pappalardo F, Pieri M, Skurk C, Lauten A, Landmesser U, Westenfeld R, Horn P, Pauschinger M, Eckner D, Twerenbold R, Nordbeck P, Salinger T, Abel P, Empen K, Busch MC, Felix SB, Sieweke JT, Møller JE, Pareek N, Hill J, MacCarthy P, Bergmann MW, Henriques JPS, Möbius-Winkler S, Schulze PC, Ouarrak T, Zeymer U, Schneider S, Blankenberg S, Thiele H, Schäfer A, Westermann D. Impella support for acute myocardial infarction complicated by cardiogenic shock. Circulation 2019;139(10):1249-58.

25. Wang X, Luke AA, Vader JM, Maddox TM, Joynt Maddox KE. Disparities and impact of Medicaid expansion on left ventricular assist device implantation and outcomes. Circ Cardiovasc Qual Outcomes 2020;13(6):e006284.

26. Chioncel O, Parissis J, Mebazaa A, Thiele H, Desch S, Bauersachs J, Harjola VP, Antohi EL, Arrigo M, Gal TB, Celutkiene J, Collins SP, DeBacker D, Iliescu VA, Jankowska E, Jaarsma T, Keramida K, Lainscak M, Lund LH, Lyon AR, Masip J, Metra M, Miro O, Mortara A, Mueller C, Mullens W, Nikolaou M, Piepoli M, Price S, Rosano G, VieillardBaron A, Weinstein JM, Anker SD, Filippatos G, Ruschitzka F, Coats AJS, Seferovic P. Epidemiology, pathophysiology and contemporary management of cardiogenic shock - a position statement from the Heart Failure Association of the European Society of Cardiology. Eur J Heart Fail 2020;22(8):1315-41. 